\title{
Cardiac Myxomas and Carcinomas: Is it Incidental or Consequential Finding?
}

\begin{abstract}
Alizadehasl $\mathrm{A}^{1 \#}$, Samimi $\mathrm{S}^{2 *}$ and Sanadgol $\mathrm{G}^{3 *}$ ${ }^{1}$ Professor of Cardiology, Echocardiologist, CardioOncologist Head of Cardio-Oncology Department \& Research Center Rajaie Cardiovascular Medical \& Research Center, Iran University of Medical Science, Tehran, Iran

${ }^{2}$ Tehran Heart Center, Tehran University of Medical Sciences, Tehran, Iran

${ }^{3}$ Cardiovascular Research Center, Shahid Beheshti

University of Medical Sciences, Tehran, Iran

"Contributed Equally to this Work

*Corresponding author: Ghazal Sanadgol, Cardiovascular Research Center, Shahid Beheshti University of Medical Sciences, Tehran, Iran
\end{abstract}

Received: August 30, 2021; Accepted: September 13, 2021; Published: September 20, 2021

\section{Letter to the Editor}

Myxoma is the most common primary intracardiac neoplasm, ranging between $0.001 \%$ to $0.03 \%$ in the general population [1] Cardiac myxomas are most frequently located in the left atrium in $80 \%$ of cases, with the remainder mostly originating from the right atrium [2]. Patients may present with various cardiovascular manifestations depending on the anatomical location (e.g., cardiac arrhythmia, embolization,...). It may also present with nonspecific constitutional sign and symptoms such as fever and weight loss $[3,4]$.

The association between cardiac myxomas and other simultaneous tumors has previously been described in the case of carney complex. Carney complex is a rare autosomal dominant syndrome caused by abnormalities in the PRKAR1A gene [5]. Patients may present with skin pigmentations and a variety of endocrine and non-endocrine tumors [5]. However, multiple reports of cardiac myxomas in patients with synchronous primary tumors have been reported, speculating that cardiac myxomas may simultaneously be present with other primary cancers, not classified as the carney complex.

A variety of malignancies have been documented that coincide Table 1: Previous studies: Association of myxomas and other carcinomas.

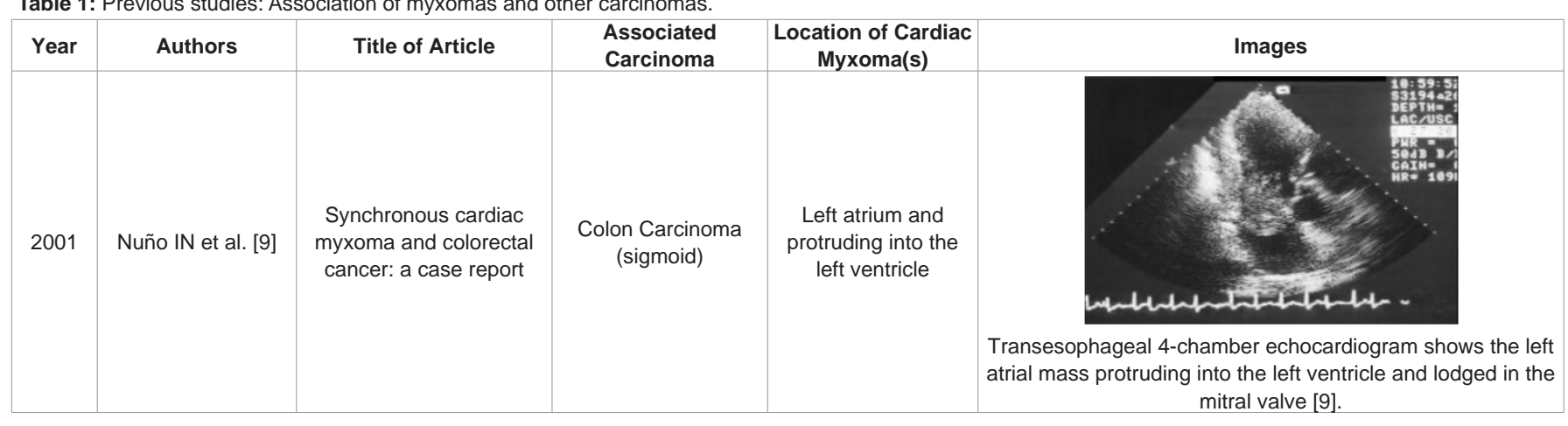

with cardiac myxomas over the years. Meir et al., encountered a left atrial myxoma in the echocardiography of a 51-year-old woman presenting with fever after receiving first chemotherapy session for invasive lobular adenocarcinoma [6]. The association between breast adenocarcinoma and cardiac myxoma was also reported by Kataoka et al. and Özer et al. [7,8]. Nuño et al. and Hajsadeghi et al., described synchronous colorectal carcinomas with a cardiac myxoma $[9,10]$.

Lazos-Ochoa et al., detected a left atrial cardiac myxoma in the autopsy of a 60-year-old woman with hepatic cirrhosis and hepatocellular carcinoma [11]. Abdulmajid et al., retrospectively noted a left atrial myxoma when evaluating computed tomography scans of a 71-year-old man treated for transitional cell carcinoma of the bladder 6 years earlier [12]. Iltumur et al., found a large left atrial myxoma while performing preoperative echocardiography for non-cardiac surgery, in a 64-year-old man with coexisting cutaneous squamous cell carcinoma [13]. Van der Merwe et al. and Gopalakrishnan et al., reported cardiac myxomas in patients with pulmonary adenocarcinoma and renal cell carcinoma, respectively $[14,15]$.

To the best of the authors' knowledge, no guides focusing on treating cardiac myxomas as a second primary tumor were identified in the literature. We propose that a two-way clinical relationship between myxoma and other primary cancers exists. On the one hand, these observations possibly emphasize the importance of echocardiography screening for patients diagnosed with cancer, especially specific types such as breast adenocarcinoma. On the other hand, this also raises the question whether patients diagnosed with myxoma should undergo screening for other primary cancers, and to what extent? Historically patients with myxoma underwent urgent surgery with no time to waste; however, nowadays this is not the case and we can use our time to screen these patients for other primary tumors. Depending on their underlying risk factors (e.g., age, smoking history,..) this could be limited to a thorough medical history and physical exam, or it could go as far as performing other paraclinical evaluations such as PET scan.
Austin J Cardiovasc Dis Atherosclerosis - Volume 8 Issue 1 - 2021 ISSN: 2472-3568 | www. austinpublishinggroup.com Sanadgol et al. @ All rights are reserved
Citation: Alizadehasl A, Samimi S and Sanadgol G. Cardiac Myxomas and Carcinomas: Is it Incidental or Consequential Finding?. Austin J Cardiovasc Dis Atherosclerosis. 2021; 8(1): 1044. 


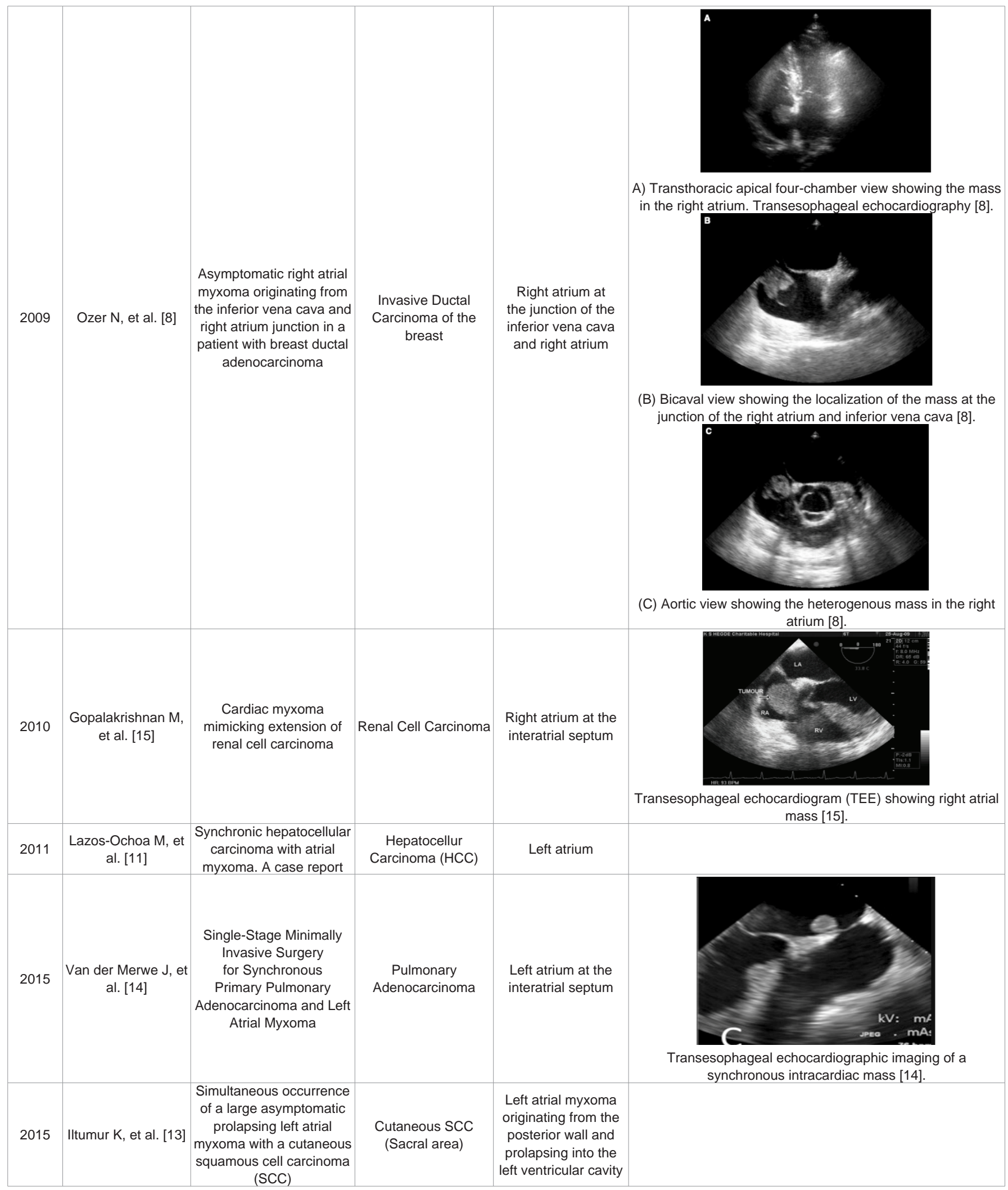




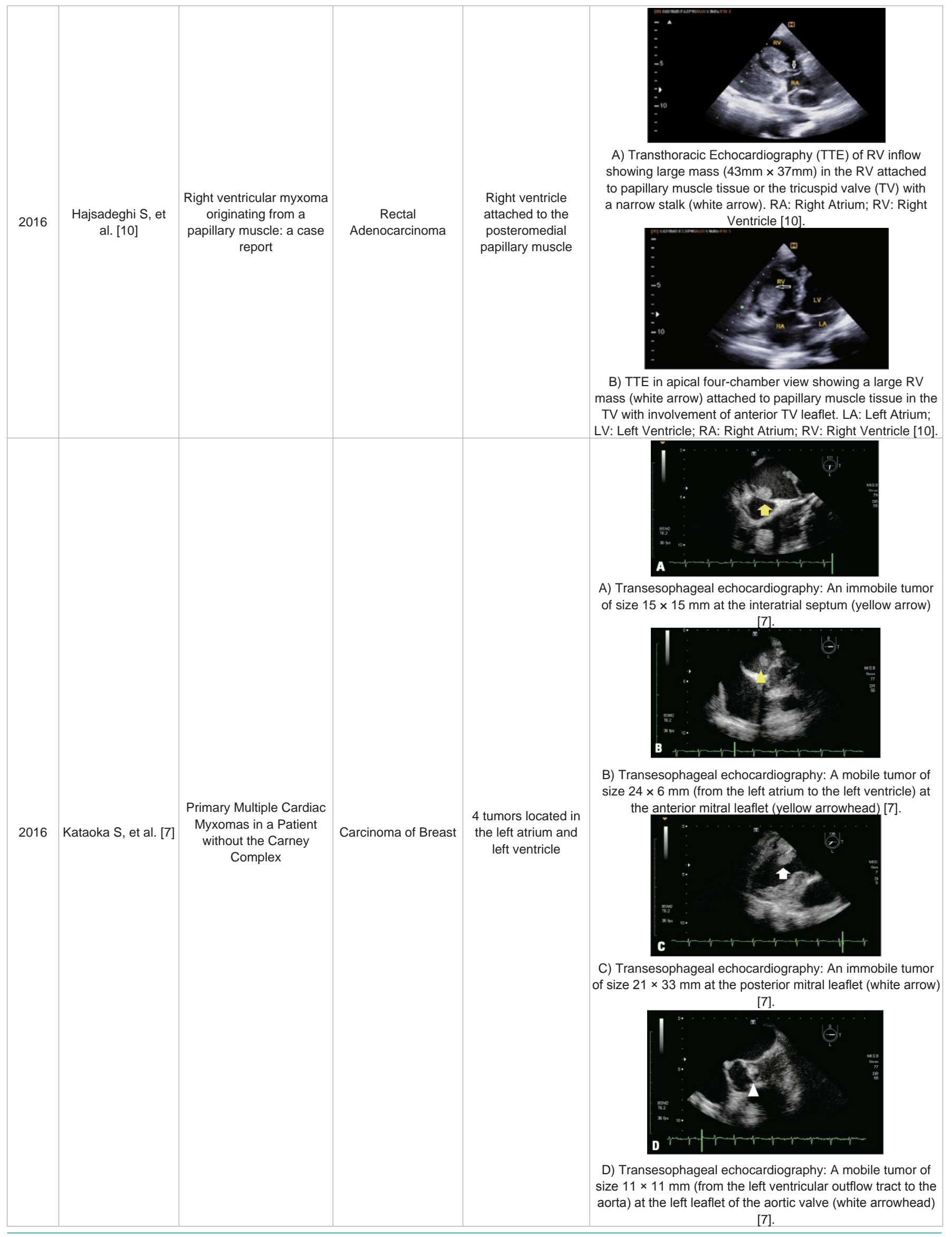




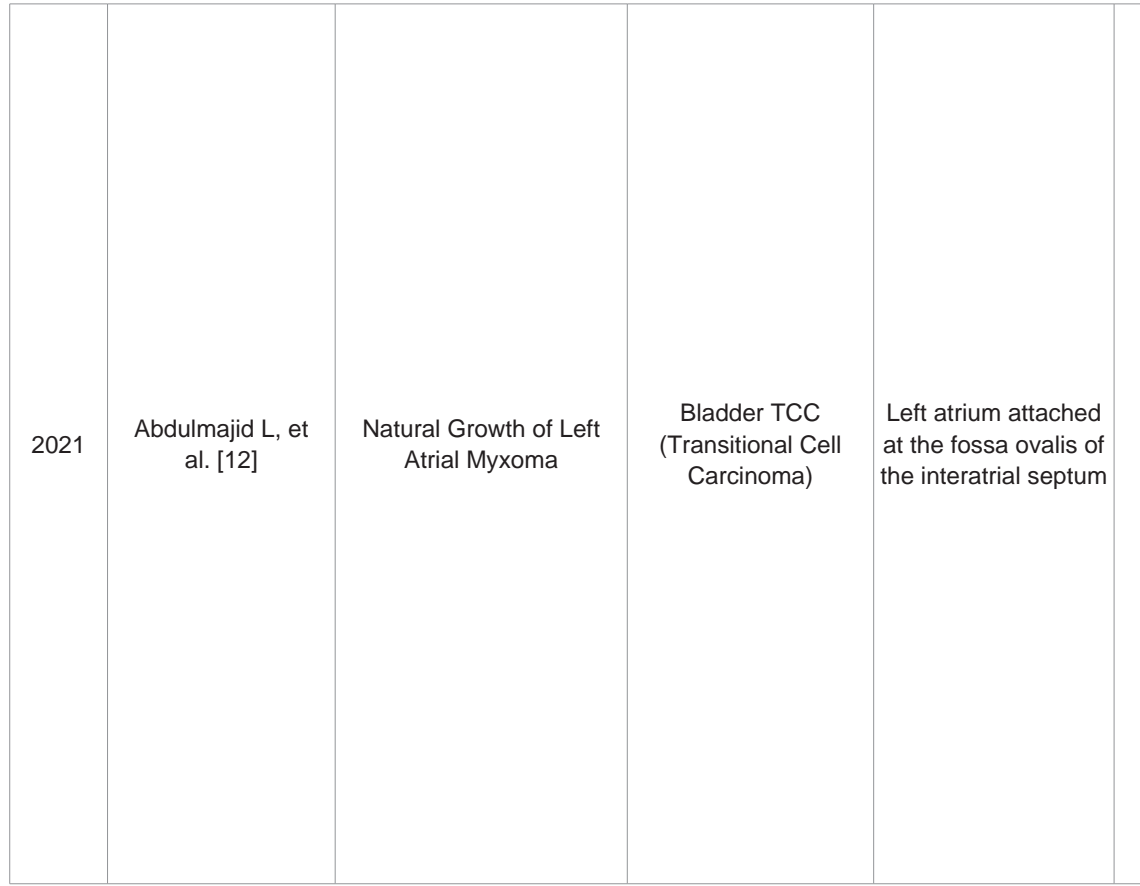

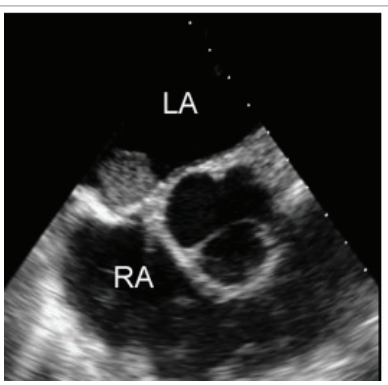

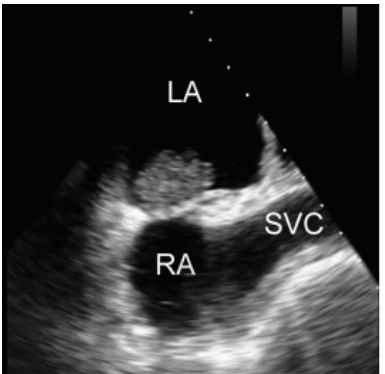

Transesophageal echocardiogram showing sessile tumor in the left atrium at the level of interatrial septum. LA: Left Atrium, RA: Right Atrium; SVC: Superior Vena Cava [12]
Our observations indicate the need for further research to evaluate the significance and possible genetic basis of this finding. Furthermore, it calls for expert opinions on how to approach and treat a patient with a cardiac myxoma and other simultaneous primary tumor. Additionally, this matter draws clinicians' attentions towards cardiac myxomas when encountering nonspecific symptoms, not otherwise defined by other diagnoses, in patients treated for various cancers.

\section{References}

1. Bossert T, Gummert JF, Battellini R, et al. Surgical experience with 77 primary cardiac tumors. Interact Cardiovasc Thorac Surg. 2005; 4: 311-315.

2. Vander Salm TJ. Unusual primary tumors of the heart. Semin Thorac Cardiovasc Surg. 2000; 12: 89-100.

3. Maisch B. Immunology of cardiac tumors. Thorac Cardiovasc Surg. 1990; 38: 157.

4. Seino $Y$, Ikeda $U$, Shimada $K$. Increased expression of interleukin 6 mRNA in cardiac myxomas. Br Heart J. 1993; 69: 565.

5. Kamilaris CDC, Faucz FR, Voutetakis A, Stratakis CA. Carney Complex. Exp Clin Endocrinol Diabetes. 2019; 127: 156-164.

6. Meir K, Maly A, Doviner V, Maly B. Intraoperative cytologic diagnosis of unsuspected cardiac myxoma: a case report. Acta Cytol. 2004; 48: 565-568.

7. Kataoka S, Otsuka M, Goto M, et al. Primary Multiple Cardiac Myxomas in a Patient without the Carney Complex. J Cardiovasc Ultrasound. 2016; 24 $71-74$
8. Ozer $\mathrm{N}$, et al. Asymptomatic right atrial myxoma originating from the inferior vena cava and right atrium junction in a patient with breast ductal adenocarcinoma. Archives of the Turkish Society of Cardiology. 2009; 37 479-482.

9. Nuño IN, Kang TY $4^{\text {th }}$, Arroyo H, Starnes VA. Synchronous cardiac myxoma and colorectal cancer: a case report. Tex Heart Inst J. 2001; 28: 215-217.

10. Hajsadeghi S, Pazoki M, Moradians V, Iranpour A, Jebeli M, Babaheidarian P. Right ventricular myxoma originating from a papillary muscle: a case report. Echocardiography. 2016; 33: 1913-1915.

11. Lazos-Ochoa M, Cruz-Gordillo AG, Murguía-Perez M. Carcinoma hepatocelular sincrónico con mixoma auricular. Informe de un caso [Synchronic hepatocellular carcinoma with atrial myxoma. A case report]. Invest Clin. 2011; 52: 170-174.

12. Abdulmajid L, El Addouli H, Paelinck B, De Bock D. Natural Growth of Left Atrial Myxoma. Ann Thorac Surg. 2021; 111: e275-e277.

13. Iltumur K, Demir T, Ariturk Z, Toprak N, Oto O. Simultaneous occurrence of a large asymptomatic prolapsing left atrial myxoma with a cutaneous squamous cell carcinoma. Heart Surg Forum. 2015; 18: E25-E27.

14. Van der Merwe J, Beelen R, Martens S, Van Praet F. Single-Stage Minimally Invasive Surgery for Synchronous Primary Pulmonary Adenocarcinoma and Left Atrial Myxoma. Ann Thorac Surg. 2015; 100: 2352-2354.

15. Gopalakrishnan M, Benjamin M, Kamath M, Thekkepurackal R. Cardiac myxoma mimicking extension of renal cell carcinoma. Interact Cardiovasc Thorac Surg. 2010; 10: 816-817. 